\title{
Regioselective nitration of aromatic substrates in zeolite cages
}

\author{
T ESAKKIDURAI, M KUMARRAJA and K PITCHUMANI* \\ School of Chemistry, Madurai Kamaraj University, Madurai 625 021, India \\ e-mail: pit12399@yahoo.com
}

MS received 5 August 2002; revised 23 December 2002

\begin{abstract}
Phenol is nitrated regioselectively by fuming nitric acid inside the cages of faujasite zeolites (dependent on the loading level) and a remarkable orthoselectivity is observed in solid state nitration. Toluene and chlorobenzene also containing ortho-/para-orienting substituents, undergo faster nitration, though the regioselectivity is less significant in zeolite media. The results are explained on the basis of diffusion and binding of phenol inside zeolite, which facilitate regioselectivity (and which is absent in toluene and chlorobenzene). Other advantages of employing zeolites as media for mild and selective nitration are also highlighted.
\end{abstract}

Keywords. Phenol, toluene, chlorobenzene, regioselective nitration, zeolites.

\section{Introduction}

Among all electrophilic substitutions, nitration of aromatic substrates is a widely studied reaction of great industrial significance as many nitroaromatics are extensively utilized as chemical feedstock for a wide range of useful materials such as dyes, pharmaceuticals etc. However, earlier technologies ${ }^{1}$ involve the use of corrosive liquid phase nitric acidsulphuric acid mixture, responsible for the generation of large amounts of wastes, which are expensive to treat. Other associated problems are overnitration, oxidation of byproducts and poor selectivity. This necessitates the need for new, novel and simpler methods for nitration which can overcome the problems. Use of nitrogen dioxide and benzene in gas phase over solid catalysts such as $\mathrm{SiO}_{2}-\mathrm{Al}_{2} \mathrm{O}_{3}$, supported sulphates, supported benzenesulphonic and ZSM-5 zeolite ${ }^{2}$ has led to nitrobenzene and the yields are generally moderate.

Liquid-phase applications involve in situ generated acyl nitrates and their bulkiness is believed to lead to improved selectivity. Environmentally friendly heterogeneous catalysts based on aluminosilicates are other attractive alternates in liquid phase. Claycop (copper(II) nitrate supported on K10-montmorillonite) has been used ${ }^{3}$ in the nitration of toluene with high para-selectivity in the presence of acetic anhydride in carbon tetrachloride. Choudary et al have effectively used $\mathrm{Fe}^{3+}$-exchanged montmorillonite catalyst for the selective nitration of chlorobenzene (up to $92 \%$ para-selectivity) and reported an isolated yield of $90 \%$ in the presence of a mixture of fuming nitric acidacetic anhydride as nitrating agent. ${ }^{4}$ Lanthanide(III) triflate which operates by generating triflic acid is also employed ${ }^{5}$ but chlorinated solvents are required and the selectivity is poor. In this context, zeolites containing cages and channels find extensive applications ${ }^{6-8}$

\footnotetext{
*For correspondence
} 
in organic reactions, either as active participants or as inert supports. Zeolite-based solid acids are potentially attractive due to the easy removability of substrate/product, catalyst recycling and possible regioselectivity due to their constraining environment. For example, in nitration of toluene using benzoyl nitrate in carbon tetrachloride, large pore mordenites $^{9}$ gives $60 \%$ selectivity. Smith et al have used zeolite $\mathrm{H}-\beta$ and acetyl nitrate to yield highly regioselective para-nitration of toluene..$^{10,11}$ Other advantages of using zeolites include quantitative yield of mononitration under mild conditions, very good selectivity, recovery and reuse of the catalysts. For the nitration of deactivated aromatic compounds also, novel nitration systems composing of nitric acid, trifluroacetic anhydride and $\mathrm{H}-\beta$ are reported. ${ }^{12}$ With emphasis on achieving higher para-selectivity to meet market demand, Choudary et al have achieved a zeolite-based methodology for the nitration of aromatic compounds. ${ }^{13}$ They have carried out nitration of toluene with various zeolite catalysts and zeolite beta of different $\mathrm{Si} / \mathrm{Al}$ ratios. Zeolite beta has proved to be the best catalyst among the zeolites used in terms of space-time yield and paraselectivity. Increased Brönsted acidity that reduces the available space is attributed to the improved para-selectivity. Same catalyst is found to nitrate aromatic substrates efficiently containing electron-withdrawing substituents as well. Halogenobenzenes undergo paraselective nitration with a nitrogen dioxide-oxygen-zeolite $\mathrm{H}-\beta / \mathrm{HY}$ as a solid inorganic catalyst. ${ }^{14}$ Recently zeolite-assisted nitration of neat toluene and chlorobenzene with a nitrogen dioxide/molecular oxygen system is reported ${ }^{15}$ and a remarkable enhancement of para-selectivity is observed. In the double Kyodai nitration of the same substrates over zeolites, high preference for the 2,4-dinitro isomer is observed at the second nitration stage. $^{16}$

It is significant to note that many of the earlier studies employ polar solvents such as acetonitrile, which tend to retain the substrate in the solvent phase rather than in the interior of the zeolite cages. Also nitration of arenes with strongly activating groups (wherein polynitration is a serious handicap to selective nitration) in zeolite environment is not explored. With these goals in mind, we have reported ${ }^{17}$ recently regioselective nitration of phenol inside the cages/channels of zeolite media using fuming nitric acid. In our attempts to delineate the mechanism in detail and also to generalize the applicability of this procedure to other aromatic compounds, we have chosen two more substrates, namely toluene and chlorobenzene, which are also ortho-/para-orienting but with reduced activation of the aryl ring and the salient features of this study are presented below.

\section{Results and discussion}

\section{$2.1 \quad$ Nitration of phenol}

In the present study, unlike earlier studies of zeolite-induced nitration of deactivated/ weakly activated aromatic substrates, HPLC grade hexane (nonpolar) is chosen as the solvent of choice, which ensures the presence of phenol predominantly inside the more polar cages/channels of zeolite (scheme 1). To demonstrate this unequivocally, nitration is carried out at two different loading levels. At a lower loading level (which corresponds to 3.6 molecules per supercage) in $\mathrm{NaY}$, picric acid (1d) is the major product followed by the $p$-nitrophenol (1c). With $\mathrm{NaX}$ zeolites, the selectivity is less pronounced compared to solution reaction and the amount of the $o$-isomer (1a) increases at the expense of (1c) and (1d). However, when the reaction carried out inside the narrow channels of molecular sieves $5 \mathrm{~A}$ and also in CsY (with much larger cations which reduce the cage size and are 


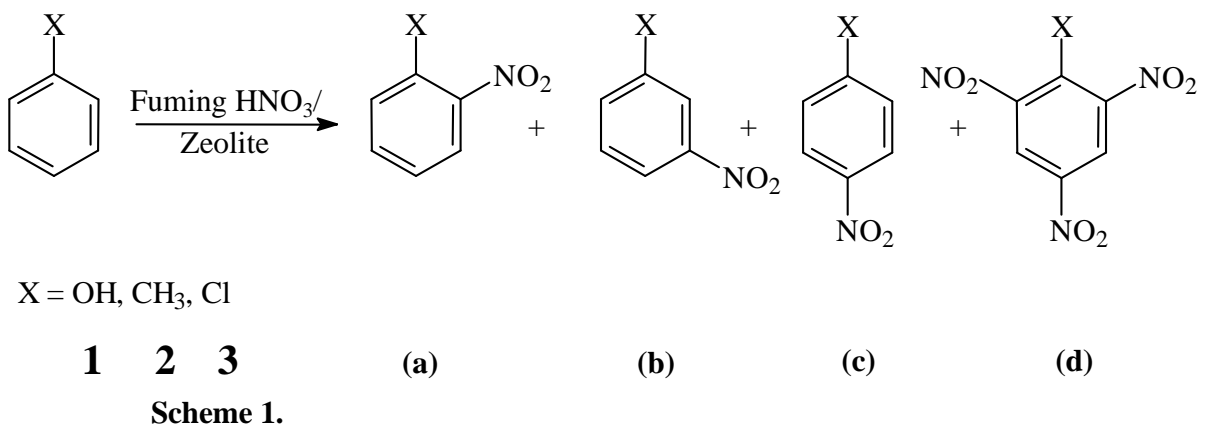

expected to exert steric hindrance to nitration), the formation of the $p$-isomer (1c) is more pronounced. With more acidic CaY zeolites, conversion is low (isolated yield is only $50 \%$ ) indicating stronger binding of the reaction mixture with the zeolite, thus limiting their utility in the present study. There is no reaction when $1: 1$ dil. $\mathrm{HNO}_{3}$ is added, as the cages are blocked by water molecules.

At a higher loading level of phenol (corresponding to 39 molecules per supercage), the influence of the zeolite environment is insignificant. As the results in table 1 indicate, in both the faujasite zeolites ( $\mathrm{NaY}$ and $\mathrm{NaX}$ ), an identical products distribution, (in which $o$ nitrophenol (1a) is the major product followed by significant amount of picric acid), is obtained. Thus with excess amount of phenol, most of them are forced to stay outside the zeolite cage and nitration occurs, predominantly in the solution phase. This assumption is supported by the observation of a similar product distribution in the absence of zeolites under identical conditions. When a narrow channel molecular sieve (inner diameter of $\sim 5 \mathrm{~A}$ ) is used, the amount of $p$-nitrophenol (1c) has increased. It is relevant to note here that zeolite-mediated $p$-selectivity within narrow pore zeolites such as ZSM-5 is well known. ${ }^{15}$

A remarkable regioselectivity in nitration is observed, when phenol is treated with fuming nitric acid in the presence of $\mathrm{NaY}$ zeolite in solid state. With a loading level corresponding to 8 molecules per supercage, the $o$-isomer (1a) is the exclusive product. The significantly higher loading level coupled with the constrained environment of zeolite in solid state forbids free mobility of phenol inside the supercage and this results in exclusive formation of $o$-nitrophenol. An increase in the amount of nitric acid, while increasing the percentage conversion, decreases the regioselectivity. The amount of $o$ isomer decreases, with a concomitant increase in the amount of picric acid, regioselectivity in the solid state is also observed in the X-type faujasites too. For example, solid state nitration of phenol in $\mathrm{NaX}$ zeolite yields only $o$-nitro phenol, (with a slight decreased percentage conversion, $19 \%$ compared to $23 \%$ in $\mathrm{NaY}$ zeolite). The result is also independent on the amount of zeolite. For example, doubling the amount of zeolite and the reagents, has also resulted in the same $o$-nitro phenol (20\% conversion), without sacrificing the selectivity.

\subsection{Nitration of toluene and chlorobenzene}

Successful regioselective nitration of phenol has prompted us to extend the nitration studies to toluene (weakly activating and $o$-/p-orienting). In an earlier work, Laszlo has 
Table 1. Percentage conversion and products distribution in nitration of phenol (1) by fuming nitric acid $^{\mathrm{a}}$.

\begin{tabular}{|c|c|c|c|c|c|c|c|}
\hline \multirow[b]{2}{*}{ Zeolite } & \multicolumn{2}{|c|}{ Amount of } & \multirow{2}{*}{$\begin{array}{c}\text { Conversion } \\
(\%)\end{array}$} & \multicolumn{3}{|c|}{ Product proportions of ${ }^{b}$} & \multirow[b]{2}{*}{$\mathrm{X}^{\mathrm{c}}$} \\
\hline & $\mathrm{HNO}_{3}(\mathrm{ml})$ & Zeolite (mg) & & $\mathbf{1 a}$ & $1 c$ & 1d & \\
\hline \multicolumn{8}{|c|}{ At lower loading level of $\mathrm{PhOH}^{d}$} \\
\hline Nil & $0 \cdot 6$ & 500 & 100 & 50 & 19 & 10 & 21 \\
\hline $\mathrm{NaY}$ & $0 \cdot 6$ & 500 & 100 & 17 & 37 & 41 & 5 \\
\hline $\mathrm{NaX}$ & $0 \cdot 6$ & 500 & 44 & 43 & 21 & 36 & - \\
\hline $\mathrm{CaY}^{\mathrm{e}}$ & $0 \cdot 6$ & 500 & 57 & 8 & 2 & - & 90 \\
\hline CsY & $0 \cdot 6$ & 500 & 76 & 16 & 76 & 8 & - \\
\hline Mol. Sieve 5 A & $0 \cdot 6$ & 500 & 100 & 11 & 72 & 16 & 1 \\
\hline $1: 1$ dil. $\mathrm{HNO}_{3}$ & $0 \cdot 6$ & 500 & nil & - & - & - & - \\
\hline
\end{tabular}

At higher loading level of $\mathrm{PhOH}^{f}$

$\begin{array}{lrrrrrrr}\text { Nil } & 0.06 & 500 & 100 & 59 & 23 & 9 & 9 \\ \mathrm{NaY} & 0.06 & 500 & 100 & 52 & 32 & 16 & - \\ \mathrm{NaX} & 0.06 & 500 & 79 & 57 & 33 & 4 & 6 \\ \mathrm{CaY} & 0.06 & 500 & 100 & 56 & 33 & 10 & - \\ \mathrm{CsY} & 0.06 & 500 & 100 & 58 & 32 & 8 & 2 \\ \text { Mol. Sieve 5 A } & 0.06 & 500 & 100 & 48 & 43 & 8 & 1\end{array}$

Solid state nitration of $\mathrm{PhOH}^{g}$

\begin{tabular}{lrrrrrrr}
$\mathrm{NaY}$ & 0.03 & 500 & 23 & 100 & - & - & - \\
$\mathrm{NaY}$ & 0.03 & 750 & 19 & 100 & - & - & - \\
$\mathrm{NaY}$ & 0.03 & 1000 & 12 & 100 & - & - & - \\
$\mathrm{NaY}$ & 0.03 & 500 & 13 & 100 & - & & - \\
$\mathrm{NaY}$ & 0.06 & 500 & 40 & 69 & 17 & 11 & 3 \\
$\mathrm{NaY}$ & 0.09 & 500 & 59 & 52 & 16 & 27 & 5 \\
$\mathrm{NaY}$ & 0.12 & 500 & 58 & 25 & 9 & 54 & 12 \\
\hline
\end{tabular}

${ }^{\mathrm{a}}$ As hexane slurry, at $0-5^{\circ} \mathrm{C}$ for $30 \mathrm{~min}$ : analysed by GC; error limit $\pm 2 \%$

${ }^{\mathrm{b}}$ Percentage conversions are normalised to 100; for structures of 1a-1d refer scheme 1

${ }^{\mathrm{c}}$ Unidentified products

${ }^{\mathrm{d}}$ With $70 \mathrm{mg}$ of $\mathbf{1}$ (corresponds to a loading level of 3.6 molecules per supercage)

${ }^{\mathrm{e}}$ Isolated yield is $\sim 50 \%$

${ }^{\mathrm{f}}$ With $800 \mathrm{mg}$ of $\mathbf{1}$ (corresponds to a loading level of 39 molecules per supercage)

${ }^{\mathrm{g}} 0.15 \mathrm{ml}(1.75 \mathrm{mmol})$ of 1 in $500 \mathrm{mg}$ of $\mathrm{NaY}$ zeolite (corresponds to a loading level of 7.5 molecules per supercage). After the addition of $\mathrm{HNO}_{3}$ at $0-5^{\circ} \mathrm{C}$ for a period of $5 \mathrm{~min}$, the solid sample was kept at room temperature for $30 \mathrm{~min}$

developed Claycop $\left(\mathrm{Cu}\left(\mathrm{NO}_{3}\right)_{2} /\right.$ montmorillonite-K10) that selectively nitrates toluene in acetic anhydride/ $\mathrm{CCl}_{4}$ with an isomer distribution of ortho 23 , meta 1 and para $76 \%{ }^{18}$ Smith has shown that mordenite and zeolite $\beta$ can play an important role in the selective mononitration of toluene, where the $p$ selectivity of $67 \%$ by using benzoyl nitrate ${ }^{9}$ and the $o / p$ isomer ratio of 0.23 by using acetyl nitrate ${ }^{10,11}$ have been achieved. Toluene has also been nitrated with isopropyl nitrate in the presence of HZSM-5, producing predominantly the $p$-isomer $(95 \%) .{ }^{20}$ In the presence of molecular oxygen and HZSM-5, neat toluene has reacted with liquid nitrogen dioxide in a regioselective manner at room temperature to yield mononitrotoluenes as main products, where the $p$-isomer predominates up to $90 \% .{ }^{16}$ 
With an objective of finding replacement of liquid sulphuric acid in the nitration of toluene and nitrotoluenes, Vassena et $a l^{20}$ have used solid acids such as silicaimpregnated sulphuric acid, H-beta, mordenite, ZSM-5 and ZSM-12 under vapour phase conditions. Zeolite-beta has provided a higher 4-nitrotoluene to 2-nitrotoluene ratio than ZSM-5, ZSM-12 and mordenite, but becomes deactivated after 5-10 $\mathrm{h}$ on-stream.

In the present study, solution nitration of toluene produces $o$ - and $p$-nitrotoluenes in a 56:39 ratio (table 2) as in previous studies of nitration. Nitration in various cationexchanged zeolites in hexane slurry causes a marginal improvement in the yield of the $p$ isomer (2c) and this is more significant in solid state nitration. Neither cation-size nor the pore dimensions of zeolite seems to influence further the selectivity of the reaction. Similarly variation in loading level of the substrate also has no effect. Though the selectivity is not as dramatic as in the case of phenol nitration, the present method of nitration of toluene has other advantages. The reaction is faster compared to solution nitration (due to the confinement of reagent and substrate inside the cage) and polynitration is totally suppressed. The poorer selectivity may be attributed to the weakly polar nature of the alkyl group, which destabilizes any interaction with the polar zeolite environment and this may have forced bulk of the substrate into the solution phase.

Nitration is also extended to a deactivated, $o-/ p$-orienting substrate namely chlorobenzene (table 3). Though the selectivity is not as significant as expected, the conversion is faster and quantitative. However in the solid state the yield of $o$-isomer increases considerably compared to solution nitration. Increased deactivation of the aryl ring (compared to phenol and toluene), has resulted in a marked improvement in the selectivity in solution phase nitration and an $o-/ p$-ratio of $27 / 71(0.38)$ is observed, in

Table 2. Percentage conversion and products distribution in nitration of toluene (2) by fuming nitric acid ${ }^{\mathrm{a}, \mathrm{b}}$.

\begin{tabular}{|c|c|c|c|c|c|c|}
\hline \multirow[b]{2}{*}{ Zeolite } & \multirow{2}{*}{$\begin{array}{c}\text { Conversion } \\
(\%)\end{array}$} & \multicolumn{3}{|c|}{ Product proportions of ${ }^{\mathrm{c}}$} & \multirow[b]{2}{*}{$X^{\mathrm{d}}$} & \multirow{2}{*}{$\begin{array}{l}\text { ortho/para } \\
\text { ratio }\end{array}$} \\
\hline & & $\mathbf{2 a}$ & $\mathbf{2 b}$ & $2 c$ & & \\
\hline Solution & 57 & 56 & 5 & 39 & - & 1.44 \\
\hline $\mathrm{NaY}$ & 100 & 48 & 5 & 44 & 3 & 1.09 \\
\hline $\mathrm{NaX}$ & 100 & 53 & 3 & 44 & - & $1 \cdot 20$ \\
\hline Mol. Sieve 5 A & 100 & 56 & 4 & 40 & - & 1.40 \\
\hline $\mathrm{RbY}$ & 100 & 57 & 4 & 39 & - & 1.46 \\
\hline $\mathrm{CsY}$ & 99 & 55 & 4 & 40 & 1 & 1.38 \\
\hline $\mathrm{NaY}^{\mathrm{e}}$ & 100 & 54 & 4 & 42 & - & 1.29 \\
\hline $\mathrm{NaY}^{\mathrm{f}}$ & 100 & 52 & 4 & 44 & 4 & $1 \cdot 18$ \\
\hline $\mathrm{NaY}^{\mathrm{g}}$ & 70 & 49 & 1 & 50 & - & 0.98 \\
\hline
\end{tabular}

${ }^{a}$ As a hexane slurry, at room temperature for $30 \mathrm{~min}$, with $500 \mathrm{mg}$ of zeolite and $0.6 \mathrm{ml}$ of fuming nitric acid, with $800 \mathrm{mg}$ of 2 (corresponds to a loading level of 32 molecules per supercage)

${ }^{\mathrm{b}}$ Analysed by GC; Error limit $\pm 2 \%$

${ }^{\mathrm{c}}$ Percentage conversion are normalized to 100; for structures of $\mathbf{2 a - 2 c}$ refer scheme 1

${ }^{\mathrm{d}}$ Unidentified products

${ }^{\mathrm{e}}$ With $80 \mathrm{mg}$ of 2 (corresponds to a loading level of 3.6 molecules per supercage)

${ }^{\mathrm{f}}$ Solid state nitration of $\mathbf{2}(0.18 \mathrm{ml})$, with $0.12 \mathrm{ml}$ of fuming nitric acid

${ }^{\mathrm{g}}$ Solid state nitration of $2(0.18 \mathrm{ml})$, with $0.03 \mathrm{ml}$ of fuming nitric acid 
Table 3. Percentage conversion and products distribution in nitration of chlorobenzene (3) by fuming nitric acid $^{\mathrm{a}, \mathrm{b}}$.

\begin{tabular}{|c|c|c|c|c|c|}
\hline \multirow[b]{2}{*}{ Zeolite } & \multirow{2}{*}{$\begin{array}{c}\text { Conversion } \\
(\%)\end{array}$} & \multicolumn{3}{|c|}{ Product proportions of ${ }^{\mathrm{c}}$} & \multirow{2}{*}{$\begin{array}{c}\text { ortho/para } \\
\text { ratio }\end{array}$} \\
\hline & & $\mathbf{3 a}$ & $3 \mathbf{c}$ & $X^{d}$ & \\
\hline Solution & 2 & 27 & 71 & 2 & $0 \cdot 38$ \\
\hline $\mathrm{NaY}$ & 100 & & 3 & - & 8 \\
\hline $\mathrm{NaX}$ & 100 & & 77 & - & 9 \\
\hline RbY & 100 & 25 & 75 & - & 3 \\
\hline $\mathrm{CsY}$ & 100 & 3 & 72 & - & $0 \cdot 3$ \\
\hline $\mathrm{NaY}^{\mathrm{e}}$ & 100 & 5 & 75 & - & $0 \cdot 33$ \\
\hline $\mathrm{NaY}^{\mathrm{f}}$ & 100 & 33 & 67 & - & $0 \cdot 49$ \\
\hline $\mathrm{NaY}^{\mathrm{g}}$ & 67 & 39 & 61 & - & 0.64 \\
\hline \multirow{6}{*}{\multicolumn{6}{|c|}{$\begin{array}{l}{ }^{\text {a }} \text { As a hexane slurry, at room temperature for } 30 \mathrm{~min} \text {, with } 500 \mathrm{mg} \text { of } \\
\text { zeolite and } 0.6 \mathrm{ml} \text { of fuming nitric acid, with } 800 \mathrm{mg} \text { of } \mathbf{3} \text { (corresponds } \\
\text { to a loading level of } 35 \text { molecules per supercage) } \\
{ }^{\mathrm{b}} \text { Analysed by GC; error limit } \pm 2 \% \\
{ }^{\mathrm{c}} \text { Percentage conversion are normalized to } 100 \text {; for structures of } \mathbf{3 a}-3 \mathrm{c} \\
\text { refer scheme } 1 \\
{ }^{\mathrm{d}} \text { Unidentified products } \\
{ }^{\mathrm{e}} \text { With } 80 \mathrm{mg} \text { of } \mathbf{3} \text { (corresponds to a loading level of } 3.3 \text { molecules per } \\
\text { supercage) }\end{array}$}} \\
\hline & & & & & \\
\hline & & & & & \\
\hline & & & & & \\
\hline & & & & & \\
\hline \multicolumn{4}{|c|}{ Solid state nitration of $3(0.14 \mathrm{ml})$, with $0.12 \mathrm{ml}$ of fuming nitric acid } & & \\
\hline
\end{tabular}

accordance with the greater thermodynamic stability of the $p$-isomer. Here also, as in toluene nitration, variation in cation size as well as loading level has not resulted in any significant variation in reaction selectivity.

Of the three substrates, phenol is the most reactive. However, it is striking to note that it is also the more selective, contrary to expectations based on reactivity-selectivity principle. This is more remarkable in solid phase nitration at a lower loading level and the other two substrates, namely toluene and chlorobenzene are insensitive to loading level variations. To account for this behaviour, we propose that phenol being more polar, enters more readily into the zeolite cages (compared to the other two substrates) and binds to the basic sites. Subsequent interaction with the active nitrating species (scheme 2) has resulted in $o$-nitration and this is more favoured in the solid state. The weakly polar nature of toluene and chlorobenzene leads to poor binding and has resulted in free mobility in and out of the cage. Consequently, loading level has no effect on nitration of these two substrates as nitration now takes place predominantly in solution phase.

Thus the observed results clearly indicate regioselective nitration of phenol and faster reactivity in toluene and nitrobenzene, in different zeolite environment. While solid state nitration ensures exclusive ortho-nitrophenol formation in $\mathrm{NaY}$, the same reaction in slurry in the presence of molecular sieve (5 A) and also with CsY (with bulkier cations) leads to predominant formation of $p$-nitrophenol. The yield of the various products also depends on the loading level of the substrate inside the supercage. By using chemical evidences, the results also demonstrate for the first time that diffusion into the cage followed by binding (more significant in lower loading level) can lead to remarkable regioselectivity in nitration. It is relevant to note here that in previous studies on nitration of phenol, $p$-substitution is achieved regioselectively and in contrast to them, the present 


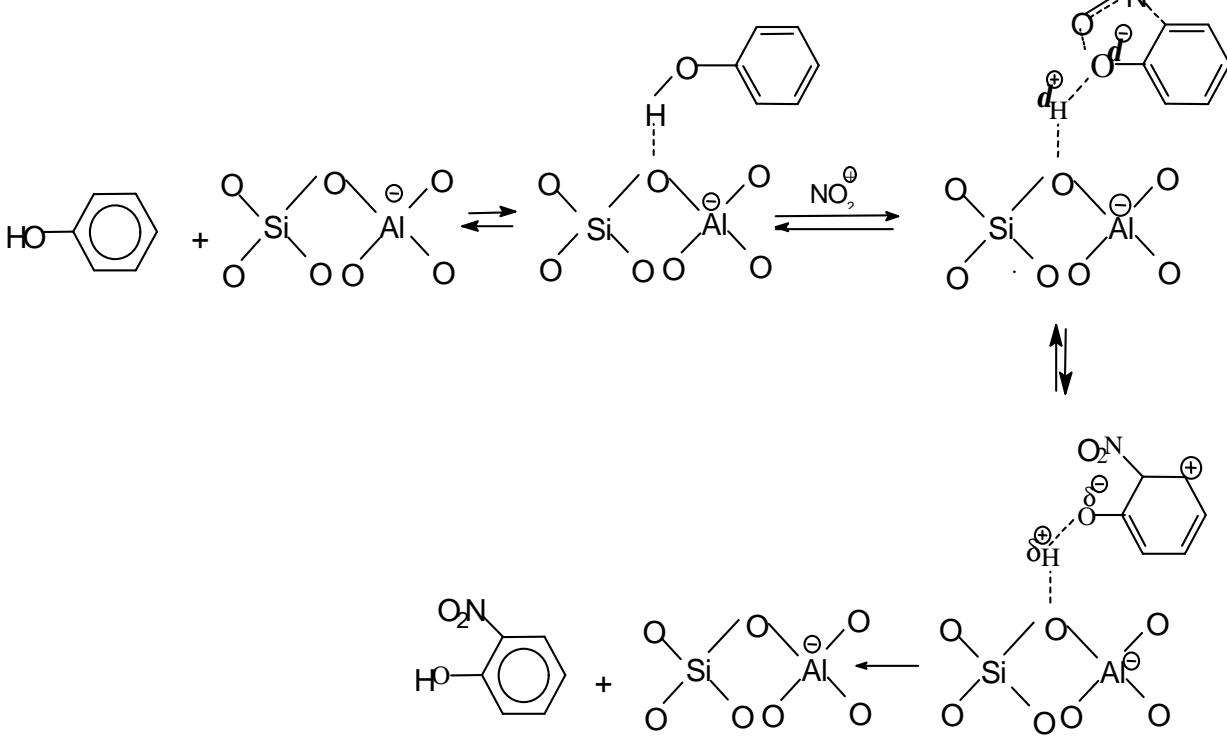

Scheme 2. Mechanism of nitration of phenol in solid phase.

study enables exclusive formation of $o$-isomer. Other advantages include significant reduction in polynitration, absence of mixed nitrating agents (no need for in situ generation of active nitrating species) and demonstration of the reaction inside the supercage (as evident from the absence of any significant variation in product distribution at a higher loading level, in which case the reaction is predominantly outside the cage). Thus zeolites provide an ideal platform for mild, safer and regioselective nitration of an electron-rich substrate too, as in the case of phenol. They are also reusable (through a thermal treatment) and are environmentally benign. Another interesting factor which differentiates zeolites from other constrained media is that as molecular sieves, they help in retaining the byproduct water in their cages.

\section{Experimental}

\subsection{General}

Toluene, phenol and chlorobenzene (E-merck) were employed after distillation. NaY zeolite was obtained from Aldrich; Molecular sieve 5 A was obtained from E Merck. The cations of interest were exchanged into the $\mathrm{NaY}$ powder by stirring with the corresponding nitrate $(10 \%)$ solution at $70^{\circ} \mathrm{C}$ for about $12 \mathrm{~h}$. The exchange was repeated at least four times. Each time after exchange, the zeolite powder was washed repeatedly with distilled water and then dried. All the zeolites were preheated at $500^{\circ} \mathrm{C}$, in muffle furnace for $6 \mathrm{~h}$, before use. 


\subsection{Nitration procedure}

3.2a Nitration of phenol in solution: In a typical experiment, to a solution of a phenol in $5 \mathrm{ml}$ of hexane kept at $0-5^{\circ} \mathrm{C}, 500 \mathrm{mg}$ of activated zeolite (preheated to $450^{\circ} \mathrm{C}$ in a muffle furnace) was added and kept stirring as a hexane slurry. Known amount of fuming nitric acid was added and the solution was magnetically stirred for $30 \mathrm{~min}$ while maintaining the temperature at $0-5^{\circ} \mathrm{C}$. After bringing the reaction mixture to room temperature, the hexane portion was removed. Overnight extraction of the zeolite using dichloromethane was carried out. The combined hexane and dichloromethane portions, after removal of the solvent, was analysed by GC.

3.2b Solid state nitration of phenol: To a solution of phenol in $5 \mathrm{ml}$ hexane, activate zeolite was added and stirred for $6 \mathrm{~h}$. Then the solvent was removed by rotary evaporation. To this solid sample (kept at $0-5^{\circ} \mathrm{C}$ ), nitric acid was added for a period of $5 \mathrm{~min}$, with continuous shaking. The reaction mixture was kept aside for $30 \mathrm{~min}$ at room temperature and then subjected to overnight extraction with dichloromethane. Products were identified by their retention times and also by coinjection with authentic samples. In all the zeolites, except $\mathrm{CaY}$, recovered mass balance was about $90 \%$.

$3.2 \mathrm{c}$ Nitration of toluene and chlorobenzene in solution: Aromatic substrates $(17.5 \mathrm{mmol})$ and preheated zeolite $(500 \mathrm{mg})$ were mixed in $5 \mathrm{ml}$ hexane (HPLC grade) and stirred together for $5 \mathrm{~min}$. After that known volume of fuming nitric acid was added drop wise for $15 \mathrm{~min}$ at room temperature. After the addition was over the mixture was stirred for $30 \mathrm{~min}$. Overnight extraction of the zeolite using dichloromethane was carried out.

$3.2 \mathrm{~d}$ Solid state nitration of toluene and chlorobenzene: The substrates and preheated zeolite were stirred with $5 \mathrm{ml}$ hexane for $1 \mathrm{~h}$ at room temperature and allowed to settle for $1 \mathrm{~h}$. The hexane portion was removed. The solid portion was washed with $2 \mathrm{ml}$ of hexane and removed again the hexane portion. The mixture was dried in air for 2-3 min and then nitrogen gas was passed through it for 5 min. Known amount of fuming nitric acid was added to it, the solid sample was kept at room temperature for $30 \mathrm{~min}$. Overnight extraction of the zeolite using dichloromethane was carried out.

\subsection{Analysis of the reaction mixture}

All GC analyses were carried out on a Shimadzu 17 A model gas chromatograph unit (SE-30 10\% capillary column, FID detector) and high purity nitrogen as the carrier gas. Retention times of phenol, toluene and chlorobenzene were taken as the internal reference. Products were identified by their retention times and also by coinjection with authentic samples.

\subsection{Spectral data of products}

In many cases products were isolated from the reaction mixture carried out in bulk. They were identified by their ${ }^{1} \mathrm{H}$-NMR spectra and also by their GC-retention times.

(1a) $90 \mathrm{MHz} \mathrm{CDCl}_{3} 7 \cdot 8 \delta(d, 1 \mathrm{H}), 7 \cdot 4 \delta(t, 1 \mathrm{H}), 6 \cdot 9 \delta(t, 1 \mathrm{H}), 6 \cdot 7 \delta(d, 1 \mathrm{H}), 6 \cdot 6 \delta(s, 1 \mathrm{H})$. 
(1c) $90 \mathrm{MHz}$ Acetone $d_{6} 7.4 \delta(d, 2 \mathrm{H}), 6.4 \delta(s, 1 \mathrm{H}), 6.2 \delta(d, 2 \mathrm{H})$.

(1d) $90 \mathrm{MHz}$ DMSO $d_{6} 8 \cdot 2 \delta(s, 1 \mathrm{H}), 7 \cdot 4 \delta(s, 2 \mathrm{H})$.

(2a) $90 \mathrm{MHz} \mathrm{CDCl}_{3} 7 \cdot 7 \delta(d, 1 \mathrm{H}), 7 \cdot 6 \delta(d, 1 \mathrm{H}), 7 \cdot 3 \delta(t, 1 \mathrm{H}), 7 \cdot 1 \delta(t, 1 \mathrm{H}), 2 \cdot 4 \delta(s, 3 \mathrm{H})$.

(2b) $90 \mathrm{MHz} \mathrm{CDCl}_{3} 7 \cdot 8 \delta(s, 1 \mathrm{H}), 7 \cdot 3 \delta(t, 1 \mathrm{H}), 7 \cdot 2 \delta(d, 1 \mathrm{H}), 7 \cdot 1 \delta(d, 1 \mathrm{H}), 2 \cdot 3 \delta(s, 3 \mathrm{H})$.

(2c) $90 \mathrm{MHz} \mathrm{CDCl} 37 \cdot 8 \delta(d, 2 \mathrm{H}), 7 \cdot 1 \delta(d, 2 \mathrm{H}), 2 \cdot 3 \delta(s, 3 \mathrm{H})$.

(3a) $90 \mathrm{MHz} \mathrm{CDCl}_{3} 7 \cdot 8 \delta(d, 1 \mathrm{H}), 7 \cdot 7 \delta(d, 1 \mathrm{H}), 7 \cdot 5 \delta(t, 1 \mathrm{H}), 7 \cdot 3 \delta(t, 1 \mathrm{H})$.

(3c) $90 \mathrm{MHz} \mathrm{CDCl}_{3} 7.9 \delta(d, 2 \mathrm{H}), 7.4 \delta(d, 2 \mathrm{H})$.

\section{Acknowledgements}

K P thanks the Department of Science and Technology, New Delhi for financial assistance. T E D thanks University Grants Commission, New Delhi for a fellowship and the Authorities of the Devanga Arts College, Aruppukottai for encouragement.

\section{References}

1. Clark J and Macquarrie D J 1997 J. Org. Proc. Res. \& Dev. 1149

2. Suzuki E, Tohmori K and Ono Y 1987 Chem. Lett. 2273

3. Laszlo P 1986 Acc. Chem. Res. 19121

4. Choudary B M, Sarma M R and Vijaya Kumar K 1994 J. Mol. Catal. 8733

5. (a) Waller F J, Barrett A G M, Braddock D C and Ramprasad D 1997 Chem. Commun. 613; (b) Waller F J, Ramprasad D, Barrett A G M and Braddock D C 1998 in Catalysis in organic reactions (ed.) F E Herkes (New York: Marcel Dekker) 289

6. (a) Clerici M G 2000 Topics in catalysis 13 373; (b) Sen S E, Smith S M and Sullivan K A 1999 Tetrahedron 33 783; (c) Corma A and Garcia H 1997 Catal. Today 38 257; (d) Holdrich W F and van Bekkum H 1991 Study Surf. Sci. Catl. 58631

7. (a) Turro N J 2000 Acc. Chem. Res. 33 637; (b) Scaiano J C and Garcia H 1999 Acc. Chem. Res. 33783

8. Ramamurthy V, Lakshminarasimhan P H, Grey G P and Johnston L J 1988 Chem. Commun. 2411

9. Smith K, Fry K, Butter M and Nay B 1989 Tetrahedron Lett. 5333

10. Smith K, Musson A and De Boos G A 1996 Chem. Commun. 469

11. Smith K, Musson A and De Boos G A 1998 J. Org. Chem. 638448

12. Smith K, Gibbins T, Millar R W and Claridge R P J 2000 J. Chem. Soc. Perkin. Trans. 1 2753

13. Choudary B M, Lakshmi Kantam M, Sateesh M, Koteswara Rao, Ram Prasad K V, Raghavan K V and Sharma J A R P 2000 Chem. Commun. 20

14. Smith K, Almeer S and Black S J 2000 Chem. Commun. 1571

15. (a) Csicsery S M 1986 Pure Appl. Chem. 58 841; (b) Pitchumani K, Warrier M and Ramamurthy V 1996 J. Am. Chem. Soc. 1189428

16. Peng X, Suzuki H and Lu C 2001 Tetrahedron Lett. 424357

17. Esakkidurai T and Pitchumani K 2002 J. Mol. Catal. A. Chem. 185305

18. (a) Laszlo P and Vandormael J 1998 Chem. Lett. 1843; (b) Cornelis A, Dedlaude L, Gerstmans A and Laszlo P 1988 Tetrahedron Lett. 295657

19. Kwok T, Jayasuriya K, Damavarapu R and Brodman B W 1994 J. Org. Chem. 594939

20. Vassena D, Kogelbauer A and Prins R 2000 Catal. Today 60275 